UN

- Conference on Straddling and Highly Migratory Fish Stocks

- Sixth Session -

- Recommendations to Governments of ECE Countries in Transition on the Management of Hazardous ChemicalsECOSOC

- Full Participation by the European Community in the Commission on Sustainable Development

ACOPS

- Russia's Northern nd Arctic Environment - Conclusions and Recommendations -

EU

357

358

142
The Environment Ministers of the EU States 77 and States of Central and Eastern Europe - Conclusions -

\section{IMO}

- Declaration on the Management of South East Asian Coastal Cities and Towns

Informal Meeting of Environment Ministers - Chairman's Conclusions -

Ozone Protocol

- Meeting of the Parties

WHO

- Helsinki Declaration
138

78

\title{
AUTHOR INDEX OF VOLUME 25
}

Blay, S.

Brown-Weiss, E.

Buckley, R.C.

Carnegie, A.R.

Green, J.

Kibel, P.S.

Kustor, P.

Loibl, G.

Lugten, G.L.

Lundmark, Th.

Mello, M. de

Miller, D.

Mlimuka, A.K.L.J.
24 Møller, H.S.

231 Müller, M.

340 Oberthür, S.

302 Ogolla, B.

24

241

311

311

223

103

73

181

52

Wäsch, Th.
111

245

144

329

Orie, K.K. 43

Ott, $\mathrm{H}$. $\quad 144$

Rest, A. $\quad 312$

Rijswijk, J.S. van $\quad 207$

Rosencranz, A. $\quad 324$

Rustomjee, S. $\quad 324$

Warnken, J. $\quad 340$

41 